\title{
Thermal Degradation of Tetrafluoroethylene and Hydrofluoroethylene Polymers in a Vacuum
}

\author{
S. L. Madorsky, V. E. Hart, S. Straus, and V. A. Sedlak*
}

\begin{abstract}
Teflon and tetrafluoroethylene photopolymers, on pyrolysis in a vacuum at $423.5^{\circ}$ to $513.0^{\circ} \mathrm{C}$, yield almost 100 percent of monomer. The rate of formation of monomer at any given temperature follows a first-order reaction and is independent of the method of preparation of polymer or its initial average molecular weight. The activation energy was determined by a pressure method and a weight method, and a value of $80.5 \mathrm{kcal}$ was found by both methods. A preliminary heating of Teflon in air at $400^{\circ}$ to $470^{\circ} \mathrm{C}$ did not change appreciably its rate of degradation into monomer when it was subsequently heated in a vacuum. Polyvinyl fluoride, 1,1-polyvinylidene fluoride, and polytrifluoroethylene were pyrolyzed in the range $372^{\circ}$ to $500^{\circ} \mathrm{C}$. The volatiles consisted in all cases of $\mathrm{HF}$ and a wax-like material consisting of chain fragments of low volatility. Polyvinyl fluoride and polytrifluoroethylene degrade to complete volatilization, whereas 1,1-polyvinylidene fluoride becomes stabilized at about 70-percent loss of weight. The rate-of-volatilization curves indicate a first-order reaction for polyvinyl fluoride, a zero-order reaction for trifluoroethylene, and an undetermined order for 1,1-polyvinylidene fluoride. The order of thermal stability for these polymers, as compared with polymethylene, is as follows: Polyvinyl fluoride $<$ polymethylene $<$ polytrifluoroethylene $<1,1$-polyvinylidene fluoride $<$ polytetrafluoroethylene
\end{abstract}

\section{Introduction}

There is very little in the literature on the thermal degradation of fluorocarbons, in general, or on fluorocarbon polymers, in particular. Swarts [1],2 Rogers and Cady [2], and Steunenberg and Cady [3] pyrolyzed a number of low molecular weight fluorocarbons in the presence of a glowing platinum filament. Lewis and Naylor [4] pyrolyzed polytetrafluoroethylene at $600^{\circ}$ and $700^{\circ} \mathrm{C}$ and at pressures varying from 5 to $760 \mathrm{~mm} \mathrm{Hg}$. The volatiles consisted of $\mathrm{C}_{2} \mathrm{~F}_{4}, \mathrm{C}_{3} \mathrm{~F}_{6}$, and $\mathrm{C}_{4} \mathrm{~F}_{8}$. In this work a study was made of the thermal degradation of a series of fluoropolymers to determine their relative thermal stability, the nature and relative amounts of the volatiles given off, and the rates of thermal degradation. This series includes polytetrafluoroethylene (Teflon) $\left[-\mathrm{C}_{2} \mathrm{~F}_{4}-\right]_{n}$, poly vinyl fluoride $\left[-\mathrm{C}_{2} \mathrm{H}_{3} \mathrm{~F}-\right]_{n}$, 1,1-polyvinylidene fluoride $\left[-\mathrm{C}_{2} \mathrm{H}_{2} \mathrm{~F}_{2}-\right]_{n}$, and polytrifluoroethylene $\left[-\mathrm{C}_{2} \mathrm{HF}_{3}-\right]_{n}$.

\section{Materials Used}

The polytetrafluoroethylene was a commercial Teflon tape, $0.07 \mathrm{~mm}$ thick. The polyvinyl fluoride and the polyvinylidene fluoride were prepared by E. I. du Pont de Nemours \& Co. The polytrifluoroethylene was prepared from the monomer by photopolymerization at $-20^{\circ} \mathrm{C}$ in the presence of di-tert-butyl peroxide and then heated overnight at $105^{\circ} \mathrm{C}^{3}$ Analyses for $\mathrm{C}, \mathrm{H}$, and $\mathrm{F}$ in the hydrofluorocarbon polymers are given in table 1 .

\footnotetext{
Present address: U. S, Public Health, Atlanta, Ga.

1 This work was performed as a part of the research project on high-temperatureresistant polymers sponsored by the Ordnance Corps, Department of the Army. resistant polymers sponsored by the Ordnance Corps, Department of the Army. The paper was presented at the 124 th meeting of th

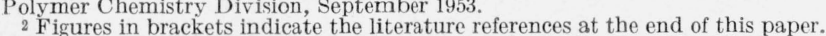

2 Figures in brackets indicate the literature references at the end of this paper. 3 The monomer and polymer were prepared by R. E. Florin and D. W. Brown,
of the Polymer Structure Section of the National Bureau of Standards. The monomer was prepared by the method of Park, Sharrah, and Lacher [5].
}

TABLE 1. Chemical analysis of hydrofuorocarbon polymers

\begin{tabular}{|c|c|c|c|c|c|c|c|}
\hline \multirow{3}{*}{ Polymer } & \multicolumn{6}{|c|}{ Analysis } & \multirow{3}{*}{$\begin{array}{l}\text { Total } \\
\text { found }\end{array}$} \\
\hline & \multicolumn{2}{|c|}{ Carbon } & \multicolumn{2}{|c|}{ Hydrogen } & \multicolumn{2}{|c|}{ Fluorine } & \\
\hline & $\begin{array}{l}\text { Theo- } \\
\text { retical }\end{array}$ & Found & $\begin{array}{l}\text { Theo- } \\
\text { retical }\end{array}$ & Found & $\begin{array}{l}\text { Theo- } \\
\text { retical }\end{array}$ & Found & \\
\hline \multirow{3}{*}{$\begin{array}{l}\text { Polyvinyl fluoride. } \\
\text { Poly viny lidene } \\
\text { fluoride } \\
\text { Polytrifluoro ethyl- } \\
\text { ene. }\end{array}$} & $\begin{array}{c}\% \\
52.2\end{array}$ & $\begin{array}{c}\% \\
52.0\end{array}$ & $\begin{array}{l}\% \\
6.6\end{array}$ & $\begin{array}{l}\% \\
6.5\end{array}$ & $\begin{array}{r}\% \\
41.2\end{array}$ & $\begin{array}{c}\% \\
41.0\end{array}$ & $\begin{array}{c}\% \\
99.5\end{array}$ \\
\hline & 37.5 & 37.4 & 3. 2 & 3. 2 & 59.3 & 58.5 & 99.1 \\
\hline & 29.0 & 29. 7 & 1.5 & 1.5 & 69.5 & & 99.2 \\
\hline
\end{tabular}

\section{Apparatus and Experimental Procedure}

The investigation of thermal degradation of this series of polymers was carried out along two lines.

1. Pyrolysis in a vacuum and fractionation and analysis of the volatile products. This procedure was followed for all of the polymers, except Teflon, using a Dewar-like molecular still, which has been described in previous papers $[6,7]$. A 20- to $30-\mathrm{mg}$ sample, either in solution or in finely divided from, was spread on a platinum tray. Size of the sample was limited so as to prevent loss of material by spattering during pyrolysis. The sample was first subjected to a preliminary heating in a vacuum for $2 \mathrm{hr}$ at about $150^{\circ} \mathrm{C}$ in order to eliminate the solvent and adsorbed gases. It was then brought to the temperature of pyrolysis by heating for $45 \mathrm{~min}$, and this temperature was then maintained for $20 \mathrm{~min}$. The following fractions were collected: I, residue; II, a waxlike material, nonvolatile in a vacuum at room temperature; III, a fraction volatile at room temperature; IV, a gaseous fraction noncondensable at the temperature of liquid nitrogen. Weights of all four fractions were determined, and, in the case of fractions III and IV, chemical composition was determined by means of the mass spectrometer. To facilitate mass-spectrometric analysis, fraction III was further subdivided by distillation into a light fraction, IIIA, and a heavy fraction IIIB. For Teflon, which requires a higher temperature of pyrolysis and which yields almost 100 percent of monomer, a different type of apparatus was used.

2. Rate of volatilization of polymers in a vacuum. This property was investigated in the case of all polymers by a weight method, and in the case of Teflon, also by a pressure 
method. The spring-balance apparatus used in the weight method is described in a previous paper [8]. The sample was limited to 5 to $8 \mathrm{mg}$ in order to avoid loss by spattering during the heating. It was placed in a platinum crucible, and the crucible was suspended by means of a 3-mil tungsten wire from a sensitive tungsten-spring balance, enclosed in a Pyrex housing, which could be evacuated to about $10^{-6} \mathrm{~mm} \mathrm{Hg}$. The crucible was heated externally, and loss of weight of the sample was determined by observing a crossline on an extension of the spring.

An apparatus for the study of rate of thermal degradation of Teflon by the pressure method is shown diagrammatically in figure 1. In this figure, $\mathrm{A}$ is a quartz tube, $3 \mathrm{~cm}$ long, 6- $\mathrm{mm}$ inside diameter, and $8-\mathrm{mm}$ outside diameter, closed at one end. This tube fits into a larger quartz tube, B, closed at one end. Tube B is sealed to a Pyrex ground joint, $\mathrm{C}$, by means of a graded seal. Samples weighing from 5 to $345 \mathrm{mg}$ were used in this apparatus. If spattering occurred during pyrolysis, it would not result in loss of material in this apparatus. This apparatus was also used in the study of pyrolysis of Teflon.

A cylindrical electric heater, not shown in the figure, was designed to maintain a uniform temperature at its center for a distance of about $4 \mathrm{~cm}$. This heater could be moved in a fixed horizontal position, so that tube A fitted approximately in the center of the heater muffle. An a-c 110-v current was fed to the heater through a voltage stabilizer and was controlled by variable resistances. The temperature was measured by means of a platinum versus platinum-10 percent rhodium thermocouple fixed permanently in the muffle of the heater, so that when the heater was moved in position for pyrolysis, the junction of the thermocouple came in contact with the closed end of tube B. The temperature inside of tube $\mathrm{A}$ was calibrated by means of an additional platinum versus platinum-10 percent rhodium thermocouple placed temporarily inside of this tube. There was no appreciable temperature gradient throughout the length of tube A. Temperature fluctuations of both thermocouples were within about $+0.5 \mathrm{deg} \mathrm{C}$.

Tube A, containing a weighed specimen of Teflon, was placed in tube B. The apparatus was evacuated to about $10^{-3} \mathrm{~mm} \mathrm{Hg}$ by means of an oil pump, not shown in the figure, and a liquid-nitrogen trap, P. Preheating of a sample of Teflon in a vacuum at about $300^{\circ}$ to $350^{\circ} \mathrm{C}$ for $48 \mathrm{hr}$ resulted in no appreciable loss in weight. The heater, which had been maintained overnight at the operating temperature, was then moved into position around tube B. It took 3 to 5 min for the temperature of the sample to reach a constant value. At the termination of an experiment, the heater was removed quickly from the apparatus.

During pyrolysis the apparatus was cut off from the evacuation pump by means of stopeock $\mathrm{D}$, while a mercurydiffusion pump, E, remained in operation. This pump was effective in removing the volatiles from the pyrolysis zone, against a back pressure of $25 \mathrm{~mm}$. The volume between this pump and stopcock D was calibrated.
Rates of volatilization of Teflon were determined from the pressure developed in the calibrated volume. The pressure was measured at time intervals by means of a multiplying manometer, $\mathrm{F}$, containing a low-vapor-pressure silicone oil in the left arm of the manometer on top of a mercury column. The manometer was calibrated by means of a three-scale McLeod gage, reading to $25 \mathrm{~mm} \mathrm{Hg}$, with a precision of 0.2 percent. The scale on the multiplying manometer could be read with a precision of $0.02 \mathrm{~mm}$. Pressures up to $6 \mathrm{~mm}$ were measured.

A sample of the fraction noncondensable at the temperature of liquid nitrogen, corresponding to fraction IV when the Dewar-like apparatus is used for pyrolysis, was obtained in the following manner. Liquid nitrogen was placed around trap L. The condensable material, corresponding to fraction III, condensed in this trap, while fraction IV remained suspended in the space between pump $\mathrm{E}$ and stopcock $\mathrm{D}$. Stopcock H over tube $\mathrm{G}$ was closed, and the tube was sealed off at $\mathrm{K}$. The contents of tube $\mathrm{G}$ were analyzed in the mass spectrometer. The weight of fraction IV was determined from its pressure, total volume, and analysis.

To obtain a sample of fraction III for analysis, the system was evacuated while trap $\mathrm{L}$ was still immersed in liquid nitrogen. With stopcock D closed, fraction III was then allowed to expand into the apparatus by removing liquid nitrogen from around trap L. Fraction III was then sampled in tube $\mathrm{G}^{\prime}$ by closing stopeock $\mathrm{H}^{\prime}$ and placing liquid nitrogen around $\mathrm{G}^{\prime}$ while the sample tube was sealed off at $\mathrm{K}^{\prime}$. Weight of fraction III was determined from its pressure, total volume and analysis.

In some experiments it was found expedient to collect the entire fraction III and to weigh it. This was done by collecting it in one of the weighed tubes, M, provided with ground joints, O. Liquid nitrogen was placed around the lower part of $\mathrm{M}$ and held there until condensation was complete. The tube was then sealed at $\mathrm{N}$, without melting it off, and subsequently weighed. Repeated experiments showed a good check between the two methods of determining total weight of fraction III.

The residue, fraction $\mathrm{I}$, was weighed in tube A. A wax-like material, fraction II, appeared in some experiments as a deposit in the cold part of tube $\mathrm{B}$, just outside the heater. The weight of this fraction was determined by subtracting the sum of weights of fractions III and IV from the total loss of weight of the sample. In cases where fraction II did not appear, there was a good balance between total weight of all fractions and original weight of sample.

\section{Pyrolysis of Teflon}

Results of pyrolysis of Teflon are shown in table 2 . This table gives also, in the last column, the results of studies of rates of thermal degradation. The experiments were carried out in the pressure apparatus shown in figure 1 and are marked $\mathrm{P}$ in column 1 of

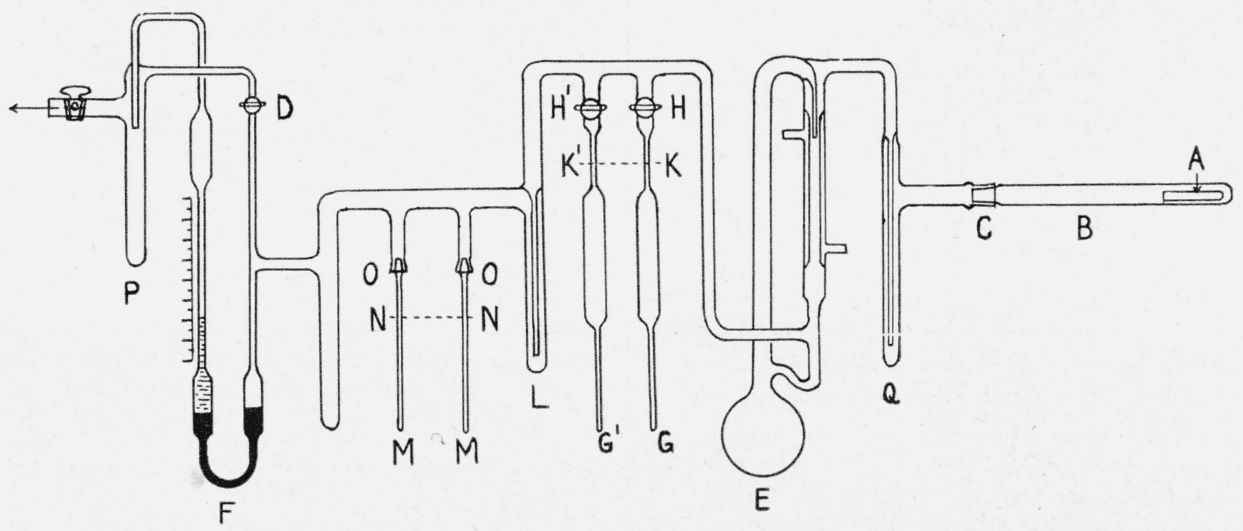

FIGURE 1. Apparatus for the study of rates of thermal degradation of polymers by the pressure method. 
TABle 2. Experimental data on thermal degradation of Teflon by the pressure and weight methods

\begin{tabular}{|c|c|c|c|c|c|}
\hline $\begin{array}{l}\text { Method } \\
\text { employed a }\end{array}$ & $\begin{array}{l}\text { Tempera- } \\
\text { ture }\end{array}$ & Duration & $\begin{array}{l}\text { Weight of } \\
\text { sample }\end{array}$ & $\begin{array}{l}\text { Total loss } \\
\text { in weight }\end{array}$ & $\begin{array}{l}\text { Rate of vola- } \\
\text { tilization }\end{array}$ \\
\hline $\begin{array}{l}\mathrm{P} \\
\mathrm{P} \\
\mathrm{P} \\
\mathrm{P} \\
\mathrm{P}\end{array}$ & $\begin{array}{l}{ }^{\circ} C \\
423.5 \\
434.5 \\
450.0 \\
454.0 \\
474.5\end{array}$ & $\begin{array}{l}\min \\
337 \\
252 \\
332 \\
108 \\
82\end{array}$ & $\begin{array}{r}m g \\
305.7 \\
345.3 \\
99.7 \\
210.5 \\
57.4\end{array}$ & $\begin{array}{l}\% \\
0.5 \\
.9 \\
4.4 \\
1.8 \\
6.4\end{array}$ & $\begin{array}{l}\% / \min \\
0.00152 \\
.00368 \\
.0136 \\
.0170 \\
.0806\end{array}$ \\
\hline $\begin{array}{l}\mathrm{W} \\
\mathrm{P} \\
\mathrm{W} \\
\mathrm{P} \\
\mathrm{P}\end{array}$ & $\begin{array}{l}480.0 \\
480.5 \\
490.0 \\
496.5 \\
499.0\end{array}$ & $\begin{array}{r}420 \\
142 \\
360 \\
56 \\
220\end{array}$ & $\begin{array}{c}6.45 \\
49.6 \\
7.01 \\
140.3 \\
7.73\end{array}$ & $\begin{array}{l}46.7 \\
17.6 \\
61.8 \\
19.6 \\
63.4\end{array}$ & $\begin{array}{l}.118 \\
.1364 \\
.240 \\
.3887 \\
.465\end{array}$ \\
\hline $\begin{array}{l}\mathrm{W} \\
\mathrm{W} \\
\mathrm{P} \\
\mathrm{P}\end{array}$ & $\begin{array}{l}500.0 \\
510.0 \\
510.5 \\
513.0\end{array}$ & $\begin{array}{l}445 \\
230 \\
149 . \\
173\end{array}$ & $\begin{array}{l}7.05 \\
6.93 \\
5.53 \\
5.25\end{array}$ & $\begin{array}{l}93.1 \\
91.5 \\
76.0 \\
90.1\end{array}$ & $\begin{array}{r}.490 \\
.952 \\
.956 \\
1.254\end{array}$ \\
\hline
\end{tabular}

a $\mathrm{P}$ and $\mathrm{W}$ refer to experiments carried out by the pressure and weight methods, respectively.

table 2. There was no wax-like (fraction II) deposit in any of these experiments. Fraction IV, on the average, amounted to 0.1 mole percent of the total volatilized part and consisted of $\mathrm{CO}$. Thus fraction III is practically equal to total loss in weight given in column 5 of table 2 . Teflon retains its original shape until about 50 percent of volatilization. Beyond this point it softens and slumps.

A method of comparing the thermal stability of a number of polymers is described in previous papers $[7,9]$. In this work the thermal stability of Teflon is shown in figure 2, compared with that of hydrofluorocarbon polymers and polymethylene. In the case of Teflon, the time required to heat a sample to the operating temperature was only 3 to $5 \mathrm{~min}$ as compared with $45 \mathrm{~min}$ for the other polymers that were pyrolyzed in the Dewar-like apparatus. In order to put the thermal-stability curve for Teflon on a comparable basis with the other curves, it was moved $15^{\circ} \mathrm{C}$ to the left. This adjustment was made on the basis of experiments with polystyrene and polytrifluoroethylene in the Dewar-like apparatus and the pressure apparatus.

In one experiment a sample of about $100 \mathrm{mg}$ of Teflon was heated in four consecutive steps to almost complete volatilization. In view of the large size of the sample, the volatiles were condensed during pyrolysis in trap Q, figure 1 , by means of liquid nitrogen to insure their complete removal from the hot zone. However, when collecting samples for weighing or for analysis, or when evacuating the apparatus between steps, trap Q was maintained at room temperature. After each step, samples from fractions III and IV were collected for analysis in tubes $\mathrm{G}$ and $\mathrm{G}^{\prime}$, respectively (fig. 1). Total weight of fraction III was obtained by collecting it in one of the tubes $\mathrm{M}$ and weighing. Allowance was made for the amount of fraction III collected in tube G. Results of the step-experiment are shown in table 3. Fraction II appears only in the last step, where the cumulative volatilization was 93.7 percent. In all the pressure experiments shown in table 2, except the last one, maximum volatilization was 76 percent, and fraction II was not observed in these experiments.

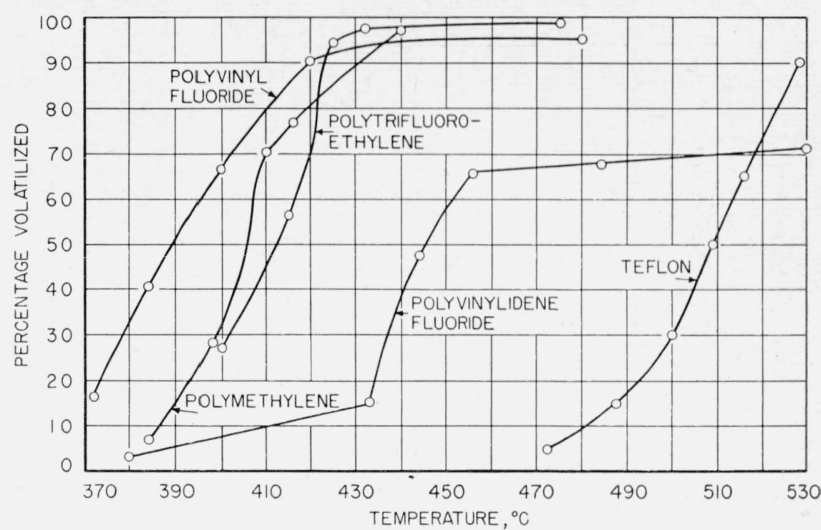

Figure 2. Relative thermal stability of Teflon, polymethylene and hydrofuoroethylene polymers.

TABLE 3. Pyrolysis of Teflon in consecutive 60-minute steps, and mass-spectrometer analysis of the volatile products

\begin{tabular}{|c|c|c|c|c|c|c|c|c|c|}
\hline \multirow{2}{*}{$\begin{array}{l}\text { Tem- } \\
\text { pera- } \\
\text { ture }\end{array}$} & \multirow{2}{*}{$\begin{array}{l}\text { Cumu- } \\
\text { lative } \\
\text { volatil- } \\
\text { ization } \\
\text { based } \\
\text { on } \\
\text { original } \\
\text { sample }\end{array}$} & \multicolumn{3}{|c|}{$\begin{array}{l}\text { Fractions based } \\
\text { on volatilized } \\
\text { part for each step }\end{array}$} & \multicolumn{5}{|c|}{$\begin{array}{l}\text { Mass-spectrometer analysis of fractions III } \\
\text { and IV combined, for each step }\end{array}$} \\
\hline & & II & III & IV & $\mathrm{C}_{2} \mathrm{~F}_{4}$ & $\mathrm{C}_{3} \mathrm{~F}_{6}$ & $\mathrm{SiF}_{4}$ & $\mathrm{CO}_{2}$ & $\mathrm{CO}$ \\
\hline $\begin{array}{l}{ }^{\circ} C \\
504 \\
509 \\
517 \\
538\end{array}$ & $\begin{array}{c}\% \\
23.2 \\
47.9 \\
71.4 \\
93.7\end{array}$ & $\begin{array}{c}\% \\
0 \\
0 \\
0 \\
8\end{array}$ & $\begin{array}{c}\% \\
99.97 \\
99.98 \\
99.95 \\
91.73\end{array}$ & $\begin{array}{c}\% \\
0.03 \\
.02 \\
.05 \\
.27\end{array}$ & $\begin{array}{c}\text { Mole \% } \\
96.8 \\
96.9 \\
96.0 \\
86.8\end{array}$ & $\begin{array}{c}\text { Mole } \% \\
2.9 \\
2.7 \\
3.0 \\
6.4\end{array}$ & $\begin{array}{c}\text { Mole } \% \\
0 \\
.1 \\
.4 \\
3.2\end{array}$ & $\begin{array}{c}\text { Mole \% } \\
0.2 \\
.2 \\
.4 \\
2.6\end{array}$ & $\begin{array}{c}\text { Mole \% } \\
0.11 \\
.07 \\
.18 \\
1.03\end{array}$ \\
\hline
\end{tabular}

In the last experiment, at $513.0^{\circ} \mathrm{C}$, where volatilization was 90.1 percent, the weight of the sample was small; and, if a fraction II appeared, it was too small to be detected.

Results of mass-spectrometer analysis are also shown in table 3 . The $\mathrm{CO}$ shown in this table appeared as fraction IV, and the rest appeared as fraction III. As seen from this table, composition of the volatiles did not vary up to at least 71.4 percent of volatilization. The $\mathrm{SiF}_{4}, \mathrm{CO}_{2}$, and $\mathrm{CO}$ might have resulted from oxygen in the polymer or, most likely, from a reaction between Teflon and quartz [10].

\section{Rates of Volatilization of Teflon}

\subsection{Determination by the weight method}

Experimental data on rate experiments with Teflon tape in the spring-balance apparatus are shown in table 2. The weight experiments are marked $\mathrm{W}$ in the first column of this table. In figure 3 the rates are plotted in percentages of the original sample per minute against percentages volatilized. By extrapolating the straight lines to zero volatilized, the initial rates are obtained. These initial rates are shown in the last column of table 2 (for experiments marked W). 


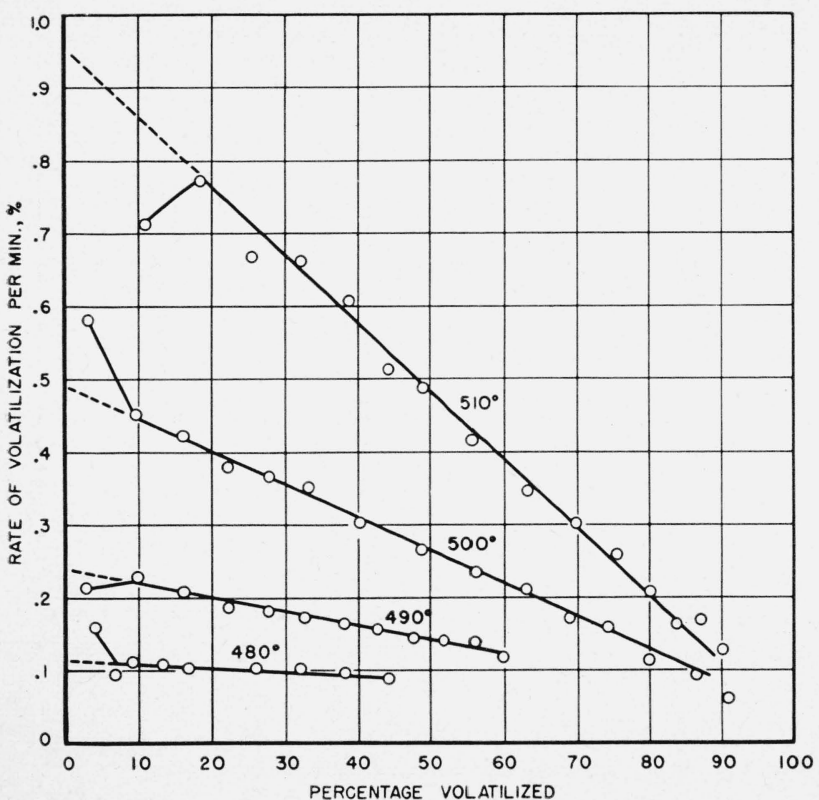

Figure 3. Rate of thermal degradation of Teflon by the weight method, as a function of percentage of volatilization.

\subsection{Determination by the pressure method}

Inasmuch as Teflon yields, on pyrolysis, mainly the monomer and a small percentage of other products, all in constant proportion and volatile at room temperature, the rate of volatilization can be obtained from a curve in which pressure of the gas in a fixed volume is plotted against time. Results of a series of rate experiments in the pressure apparatus are shown in the last column of table 2. An example of a pressure-time curve is shown by the curved line in figure 4 for a rate experiment made at $513^{\circ} \mathrm{C}$. This experiment is shown in table 2 as the last experiment of the series.

The condition for a first-order reaction is that the plot of $\ln (a-x)$, where $(a-x)$ is the residue, against time, $t$, is a straight line [11]. In such a plot, rate of reaction, $k$, is the slope of the straight line, and can thus be evaluated. The straight line in figure 4 was obtained by plotting log of residue, calculated in terms of pressure, against time for the $513.0^{\circ}$ experiment. Using such curves as shown in figure 4, the rates shown in the last column of table 2 were obtained for the experiments marked $\mathrm{P}$.

To determine the effect of heating Teflon in air on rates of volatilization, samples were heated in air at $400^{\circ}, 425^{\circ}$, and $450^{\circ} \mathrm{C}$. The amounts volatilized were about the same as in a vacuum. When the samples were heated at $470^{\circ}$, the amount volatilized was slightly greater in air than in a vacuum. The residues from air-heated samples were pyrolyzed in a vacuum. The behavior of these residues, with regard to rate and products of volatilization, was about the same as for original Teflon.

The effect of thickness of the Teflon specimen on rate of volatilization in a vacuum was determined by

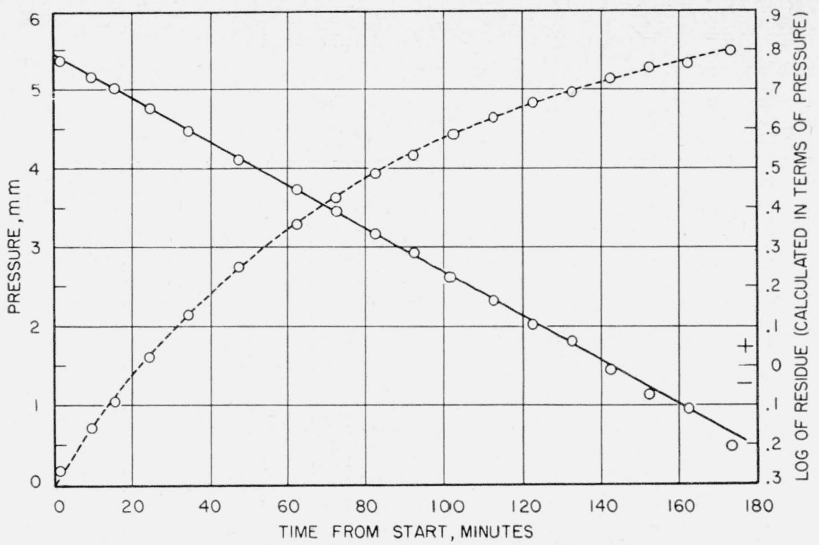

Figure 4. Rate of thermal degradation of Teflon at $513.0^{\circ} \mathrm{C}$ by the pressure method.

......., Time versus pressure plot; __ t time versus log of residue plot.

the following experiment. A $1.3-\mathrm{mm}$ cube of Teflon was pyrolyzed at $514.5^{\circ}$ for $133 \mathrm{~min}$. Total volatilization was 78.3 percent, and the rate was the same as for tape Teflon pyrolyzed under similar conditions. In another experiment, a $1.9-\mathrm{mm}$ cube of Teflon was pyrolyzed at $495^{\circ}$. Initially, the rate was slow, but it soon reached the value for tape Teflon.

Some photopolymers of tetrafluoroethylene were prepared [12] by irradiating the monomer with ultraviolet light in the presence of $\left(\mathrm{CF}_{3}\right)_{2} \mathrm{Hg}$, benzoyl peroxide, $\mathrm{CF}_{3} \mathrm{I}$, and di-tert-butyl peroxide as catalysts; also in the absence of a catalyst. On pyrolysis in a vacuum, these polymers had the same rates of volatilization as the tape Teflon.

The activation energy is obtained by plotting logarithms of rate versus inverse of absolute temperature. This plot is shown in figure 5 for the weight and the pressure experiments. All the points fall on a straight line. Multiplying the slope of this line by $2.303 R$, where $R$ is the gas constant, $1.987 \mathrm{cal} / \mathrm{deg}$, a value of $80.5 \mathrm{kcal}$ is obtained, which is the activation energy for the thermal degradation of Teflon. The frequency factor, $A$, as calculated by means of Arrhenius' equation, has a value of $4.7 \times 10^{18}$, when rates are expressed in fraction per second.

\section{Pyrolysis of Polyvinyl Fluoride, Polyviny- lidene Fluoride, and Polytrifluoroethylene}

Pyrolysis of these polymers was carried out in the Dewar-like molecular still. Experimental details are shown in table 4 . The gaseous fraction, IV, amounted in all cases to less than 0.1 percent of the total volatilized part. Mass-spectrometer analysis showed it to consist of hydrogen and carbon monoxide. The less volatile fraction, III, was found on mass-spectrometer analysis to consist, in the cases of polyvinyl and polyvinylidene fluorides, mainly of $\mathrm{SiF}_{4}, \mathrm{H}_{2} \mathrm{O}$, and some unidentified hydrofluorocarbon fragments. In the case of polytrifluoroethylene, this fraction, in addition to $\mathrm{SiF}_{4}$ and $\mathrm{H}_{2} \mathrm{O}$, contained some $\mathrm{CO}_{2}$. 


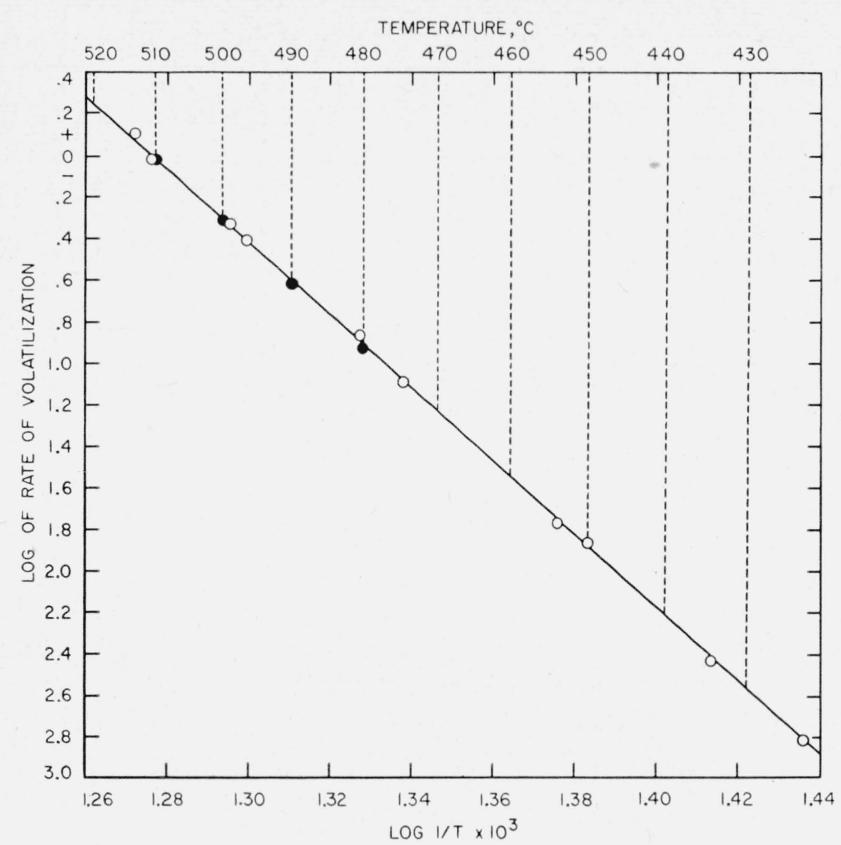

Figure 5. Activation energy slope for the thermal degradation of Teflon.

-, Weight method; $\bigcirc$, pressure method.

TABLE 4. Pyrolysis of hydrofluorocarbon polymers ${ }^{a}$

\begin{tabular}{|c|c|c|c|c|c|}
\hline \multirow[b]{2}{*}{ Experiment } & \multirow{2}{*}{$\begin{array}{l}\text { Weight } \\
\text { of } \\
\text { sample }\end{array}$} & \multirow{2}{*}{$\begin{array}{l}\text { Temper- } \\
\text { ature }\end{array}$} & \multirow{2}{*}{$\begin{array}{c}\text { Total } \\
\text { volatilized } \\
\text { part }\end{array}$} & \multicolumn{2}{|c|}{$\begin{array}{l}\text { Fraction III } \\
(\mathrm{HF})-\end{array}$} \\
\hline & & & & $\begin{array}{c}\text { Based on } \\
\text { volatilized } \\
\text { part }\end{array}$ & $\begin{array}{l}\text { Based on } \\
\text { original } \\
\text { sample }\end{array}$ \\
\hline \multicolumn{6}{|c|}{ Polyvinyl fluoride } \\
\hline $\begin{array}{l}1 \\
2 \\
3 \\
4 \\
5\end{array}$ & $\begin{array}{c}m g \\
22.8 \\
21.8 \\
26.7 \\
18.8 \\
26.2\end{array}$ & $\begin{array}{l}{ }^{\circ} \mathrm{C} \\
372 \\
385 \\
400 \\
420 \\
480\end{array}$ & $\begin{array}{c}\% \\
16.5 \\
40.7 \\
66.4 \\
90.4 \\
95.3\end{array}$ & $\begin{array}{c}\% \\
49.7 \\
37.3 \\
28.2 \\
27.5\end{array}$ & $\begin{array}{r}\% \\
8.2 \\
15.2 \\
18.7 \\
26.2\end{array}$ \\
\hline \multicolumn{6}{|c|}{ Polyvinylidene fluoride } \\
\hline $\begin{array}{l}1 \\
2 \\
2 \\
3 \\
4 \\
5 \\
6 \ldots \ldots\end{array}$ & $\begin{array}{l}26.1 \\
21.3 \\
19.6 \\
29.6 \\
29.2 \\
27.1\end{array}$ & $\begin{array}{l}380 \\
433 \\
444 \\
456 \\
484 \\
530\end{array}$ & $\begin{array}{r}3.7 \\
15.2 \\
47.6 \\
65.5 \\
67.5 \\
71.0\end{array}$ & $\begin{array}{c}41.4 \\
51.5 \\
48.0\end{array}$ & $\begin{array}{r}6.3 \\
24.5 \\
34.2\end{array}$ \\
\hline \multicolumn{6}{|c|}{ Polytrifluoroethylene } \\
\hline $\begin{array}{l}1 \\
2 \\
3 \\
4 \\
5 \\
4\end{array}$ & $\begin{array}{l}23.7 \\
25.5 \\
17.1 \\
23.5 \\
34.8\end{array}$ & $\begin{array}{l}400 \\
415 \\
425 \\
432 \\
475\end{array}$ & $\begin{array}{l}27.4 \\
56.5 \\
94.4 \\
97.7 \\
98.7\end{array}$ & $\begin{array}{r}8.0 \\
5.3 \\
5.7 \\
. .-\end{array}$ & $\begin{array}{r}9.0 \\
12.3 \\
-23.0 \\
\end{array}$ \\
\hline
\end{tabular}

a Duration of each experiment- -45 minutes of heating to pyrolysis temperature, followed by 30 minutes of pyrolysis at this temperature.

The $\mathrm{SiF}_{4}$ and $\mathrm{H}_{2} \mathrm{O}$ are due to a reaction between $\mathrm{HF}$, resulting from pyrolysis, and $\mathrm{SiO}_{2}$ in the glass apparatus. This reaction can take place at room temperature in the presence of a trace of $\mathrm{H}_{2} \mathrm{O}$. Formation of $\mathrm{H}_{2} \mathrm{SiF}_{6}$ from $\mathrm{HF}$ and $\mathrm{SiF}_{4}$ is possible, but, under conditions of vacuum and insufficient amount of $\mathrm{H}_{2} \mathrm{O}$, hydrofluorosilicic acid tends to decompose back into $\mathrm{HF}$ and $\mathrm{SiF}_{4}$. Pyrex also contains some $\mathrm{B}_{2} \mathrm{O}_{3}$, which might react with $\mathrm{HF}$, but there was no evidence in the mass-spectrometer analysis of the presence of $\mathrm{BF}_{3}$. Aluminum oxide, ordinarily present in the glass, does not react appreciably with $\mathrm{HF}$ at room temperature.

The $\mathrm{CO}_{2}$ found in fraction III from polytrifluoroethylene could not be explained on the basis of a reaction between fluorocarbon and $\mathrm{SiO}_{2}$ of the glass. According to White and Rice $[10]$ such a reaction takes place at elevated temperatures, and in this case the polymer was in contact during pyrolysis with platinum, and the polymer fragments were in contact with glass at low temperatures. It is possible that the polytrifluoroethylene contained some oxygen as a part of its structure. This oxygen, on reacting with the polymer, could give $\mathrm{CO}_{2}$. No analysis for oxygen in the original polymer was made because of the difficulty involved in such analysis in the presence of fluorine. The fluorocarbon tends to react with the glass container at the elevated temperature employed in analysis, and $\mathrm{CO}_{2}$ results from such a reaction. The $\mathrm{CO}$ detected in fraction IV from pyrolysis of hydrofluorocarbon polymers could come from oxygen as an impurity.

Fraction III was calculated in the case of all three polymers to $\mathrm{HF}$ on the basis of $\mathrm{SiF}_{4}$ content in the volatiles. This fraction is shown in the last two columns of table 4 in weight percent of the total volatilized part and in weight percent of sample. Fraction II consisted of a nonvolatile light-brown wax-like deposit, soluble in acetone. Because fraction IV was only about 0.1 percent, fraction II, in percentage of total volatilized part, can be taken as the difference between 100 and the percentage of fraction III, in terms of volatilized part, given in table 4. Mass-spectrometer analysis of fraction III indicated the presence of hydrofluorocarbon molecules of molecular weight up to 150 . However, in calculations of $\mathrm{HF}$ as fraction III, these hydrofluorocarbon fragments were included in fraction II because their nature could not be identified. Judging from results of pyrolysis of other polymers, in the temperature range of $370^{\circ}$ to $430^{\circ} \mathrm{C}$ [7, 9], fraction II from the hydrofluoropolymers should have an average molecular weight of about 600 to 700 . The residue, fraction $I$, from all three polymers appeared light brown during the early stages of degradation and dark brown toward the end. In the case of polyvinylidene fluoride, the residue, above 50 percent of volatilization, appeared black.

As can be seen from table 4, polyvinyl fluoride and polytrifluoro ethylene volatilize almost 100 percent. Polyvinylidene fluoride, however, seems to become stabilized at around 65 percent of volatilization. When the temperature of pyrolysis was raised from $456^{\circ}$ to $530^{\circ} \mathrm{C}$, the additional loss in weight was only 5.5 percent. In one experiment in the pressure apparatus a $69.3-\mathrm{mg}$ sample of polyvinylidene fluoride was heated in a vacuum from room temperature to $650^{\circ} \mathrm{C}$ in $80 \mathrm{~min}$. Total loss by volatilization was 


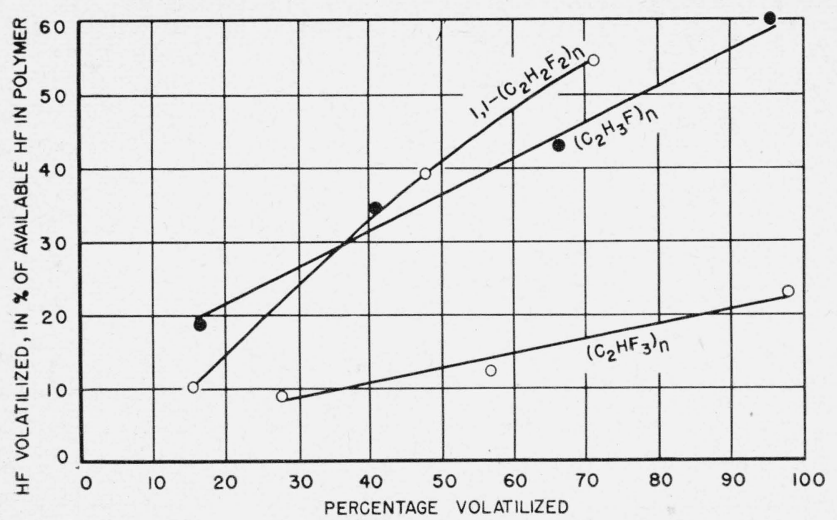

Figure 6. Yield of $\mathrm{HF}$, in percentage of total available $\mathrm{HF}$ in the polymer, as a function of total percentage of volatilization from the polymer.

76.1 percent. The residue was further heated in the apparatus for 30 min by means of a Meker burner, applied to the outer tube B (fig. 1). Additional loss in weight was 1.5 percent of the original sample. The residue resembled coke in hardness and appearance. In another experiment a 78.9-mg sample of polyvinylidene fluoride was heated gradually in the same apparatus from room temperature to $500^{\circ}$ during $2 \mathrm{hr}$ and then kept at $500^{\circ}$ for $1 \mathrm{hr}$. Loss of weight by volatilization was 70.3 percent. Chemical analysis showed that the residue still contained 1.7 percent of $\mathrm{H}$ and 12.6 percent of $\mathrm{F}$ by weight.

Relative thermal stability curves for the three hydrofluorocarbon polymers are shown in figure 2, in comparison with similar curves for Teflon and polymethylene. The polymethylene curve is based on pyrolysis experiments made in the Dewar-like apparatus at five temperatures. Experimental conditions were about the same as in the case of the hydrofluorocarbon polymers. The polymethylene was a nonbranched, high-molecular weight polymer of the same stock that was used by Mandelkern and associates [13] in their study of intrinsic viscosity.

Loss of HF from the three hydrofluorocarbon polymers during pyrolysis, in percentage of available $\mathrm{HF}$ in the polymer, is plotted against percentage of volatilization in figure 6 .

\section{Rates of Volatilization of Hydrofluoro- carbon Polymers in a Vacuum}

In view of the complex nature of the thermal degradation of polyvinyl fluoride, polyvinylidene fluoride, and polytrifluoroethylene, involving splitting off of $\mathrm{HF}$, in addition to scissions of the chain, activation energies would be of little significance. However, the shape of the rate curves might be of interest as revealing details of the mechanism of thermal degradation. One rate curve for each of these polymers is shown in figure 7. The important aspect of these curves is not their relative rate, for this is shown in figure 2 , but their shape. The polyvinvl-fluoride curve beyond 19 percent of volatiliza-

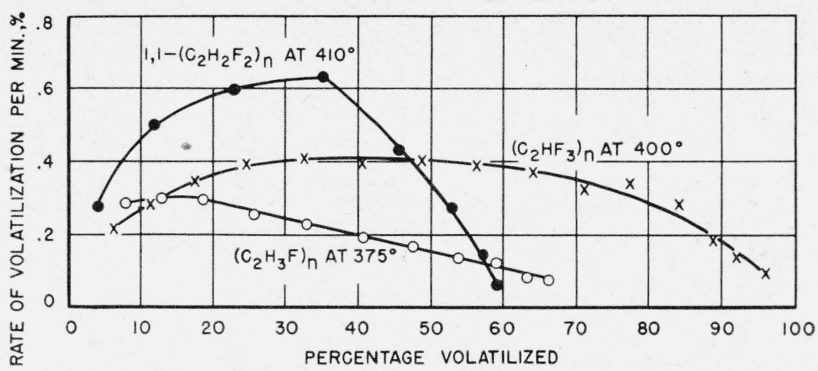

FIgURE 7. Rates of thermal degradation of hydrofluoroethylene polymers, as a function of percentage of volatilization.

tion resembles that of a first-order reaction, whereas the polytrifluoroethylene curve resembles that of a zero-order reaction, at least in the range 25 to 80 percent of volatilization. The rate curve for polyvinylidene fluoride is conditioned primarily by the stabilization effect, above 50 percent of volatilization.

\section{Discussion of Results}

\subsection{Teflon}

In considering the mechanism of thermal degradation of Teflon, the following experimental facts should be borne in mind: The monomer yield is almost 100 percent; the material softens and slumps above about 50 percent of volatilization; the reaction is of first order; and the rate of volatilization is very likely independent of chain length, because Teflon, tetrafluoroethylene photopolymers, and air-heated Teflon all had the same rates of volatilization and the same volatile products.

On the basis of these facts, a mechanism involving unzipping of monomer units at free-radical ends of chains is assumed. The absence of fraction II would seem to indicate that the kinetic chain length is very long, so that once unzipping is initiated, it continues in most cases to the end of the molecule. Initiation may take place when free radicals form either through breaking off of foreign elements, or groups of elements, at the chain ends, or when a break occurs in the chain due to thermal agitation. Such thermal breaks are more likely to occur in the long chains than in the short chains, and result in free-radical chain ends. The general trend during pyrolysis is for the average chain length to become shorter, as indicated by the fact that the residue softens at about 50 percent volatilization. On the other hand, the shorter the chains, the greater will be the tendency for their recombination at their free-radical ends.

\subsection{Hydrofluorocarbon polymers}

The substitution of one or more hydrogen atoms for fluorine on the chain changes radically the nature of the polymer. Unlike polytetrafluoroethylene, none of the hydrofluorocarbon polymers yield any appreciable amount of monomer. Instead of monomer, the volatiles consist of $\mathrm{HF}$ and chain fragments of 
various sizes. The following mechanism is suggested. When HF breaks off, a double-bond forms in the chain at that point. A break in the chain may then occur at a $\mathrm{C}-\mathrm{C}$ bond in $\beta$-position to this double bond. This break, as in polyethylene, results in one end of the break becoming saturated and the other end forming a double bond. In polyvinylidene fluoride, where there is more available $\mathrm{HF}$, double bonds will form in the chain at an accelerated rate until they appear in conjugated position. This causes a lesser degree of chain scissions and the chain becomes stabilized. The yield of fraction III (HF), in percentage of volatilized part or in percentage of sample (table 4), is greater from polyvinylidene fluoride than from polyvinyl fluoride, which is to be expected. However, in percentage of total available $\mathrm{HF}$ on the chains, the yield of $\mathrm{HF}$ is about the same (fig. 6).

In the case of polytrifluoroethylene, the amount of $\mathrm{HF}$ liberated is small as compared with polyvinyl and polyvinylidene fluorides (fig. 6). It seems that an abundance of fluorine on the polymer chain is less favorable to splitting off of $\mathrm{HF}$ than a similar abundance of hydrogen. Discoloration of fraction II and of the residue in all three polymers is probably due to runs of conjugated double bonds, the same as was found in the pyrolysis of polyvinyl chloride [14]. Discoloration was found more pronounced in the case of polyvinylidene fluoride than in the cases of the other two hydrofluorocarbon polymers.

\section{References}

[1] F. Swarts, Bul. soc. chim. Belg. 42, 114 (1933).

[2] G. C. Rogers and G. H. Cady, J. Am. Chem. Soc. 73, 3513 (1952).

[3] R. K. Steunenberg and G. H. Cady, J. Am. Chem. Soc. 74, 4165 (1952).

[4] E. E. Lewis and H. A. Naylor, J. Am. Chem. Soc. 69, 1968 (1947).

[5] J. D. Park, M. L. Sharrah, and J. R. Lacher, J. Am. Chem. Soc. 71, 2339 (1949).

[6] S. L. Madorsky and S. Straus, J. Research NBS 40, 417 (1948) RP1886; Ind. Eng. Chem. 40, 848 (1948).

[7] S. L. Madorsky, S. Straus, D. Thompson, and L. Williamson, J. Research NBS 42, 499 (1949) RP1989; J. Polymer Sci. 4, 639 (1949).

[8] S. L. Madorsky, J. Polymer Sci. 9, 133 (1952).

[9] S. Straus and S. L. Madorsky, J. Research NBS 50, 165 (1953) RP2405.

[10] L. White, Jr., and O. K. Rice, J. Am. Chem. Soc. 69, 267 (1947).

[11] S. Glasstone, Textbook of physical chemistry, 2d ed., p. 1046 (D. Van Nostrand Co., New York, N. Y., 1946).

[12] R. E. Florin, L. A. Wall, D. W. Brown, and L. Hymo (paper in preparation).

[13] L. Mandelkern, M. Hellmann, D. W. Brown, D. E. Roberts, and F. A. Quinn, Jr., J. Am. Chem. Soc. $\mathbf{7 5 ,}$ 696 (1953).

[14] Donald Druesedow and C. F. Gibbs, Symposium on Polymer Degradation Mechanisms, National Bureau of Standards, 1953.

WASHington, July 23, 1953. 